At lower and higher E.M.F. values, etching or roughening of the specimen takes place, with gas evolution, but at still higher values (beyond the point $P$ ) the phenomenon of 'polishing' (now accompanied by gas evolution) reappears. For specimens previously abraded with fine emery paper (finishing with Hubert 0000 ) as in our experiments, 15 minutes at 6 volts suffices for the electrolytic treatment ; coarser initial surfaces can, however, be satisfactorily dealt with in appropriately longer times.
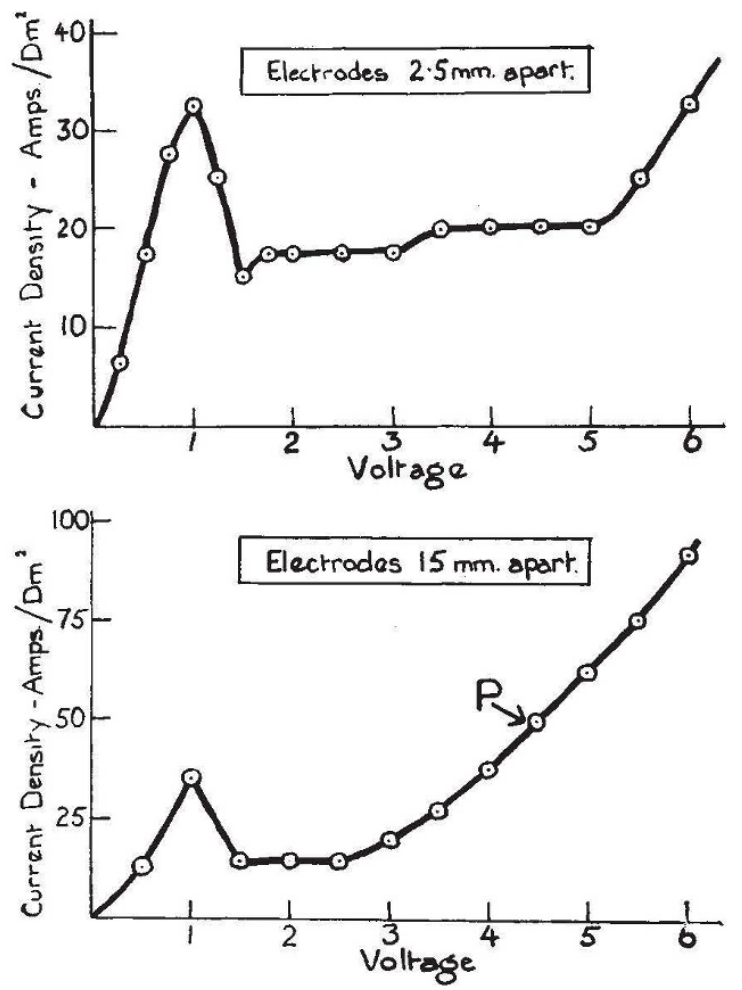

We have followed Jacquet in the use of the term 'polishing'; neither of the alternatives that have been proposed ('brightening' and 'smoothing') is adequate, since each refers to one component only of the process actually involved.

W. H. J. VERNON.

E. G. Strroud.

Chemical Research Laboratory,

Teddington, Middlesex. Aug. 10.

1 NATURE, 135, 1076 (1935).

Bull. Soc. chim., 3, 705 (1936).

${ }^{3}$ C.R., 205, 1232 (1937). See also Trans. Electrochem. Soc., 69, 629 (1936); J. Electrodep. Tech. Soc., First Internat. Conf., 1937.

${ }^{4}$ Elektrokemiska Aktiebolaget, German Pat., 645, 979 (June 9, 1937).

\section{Melting Point of High-Purity Silicon}

Hoffmann and Schulze ${ }^{1}$ have recently determined the melting point of high-purity silicon $(99.89$ per cent) and of commercial silicon (98 per cent), and give the values $1,411^{\circ} \pm 2^{\circ} \mathrm{C}$. and $1,409^{\circ} \pm 2^{\circ} \mathrm{C}$. respectively.

When high-purity silicon was first prepared at the National Physical Laboratory by Tucker ${ }^{2}$, I determined the melting point of a very pure sample, but the results were not published. In comparison with the above, the data I obtained are of considerable interest.

The silicon, in granular form, was packed tightly in a silica pot, the top of which was sealed, with a silica thermocouple sheath passing through to a depth of about a quarter of the height from the bottom of the pot. The temperatures of melting and of freezing were measured by means of a calibrated 5/20 rhodium-platinum thermocouple.

The results obtained were as follows:

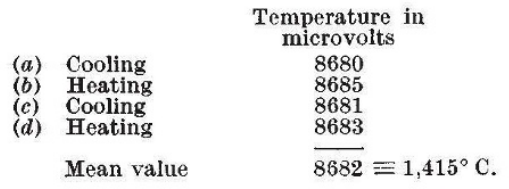

The analysis of the silicon after the above experiment had been carried out is given below and was the same as that of the original batch of material.

\begin{tabular}{ccc} 
Insoluble & 0.01 & per cent \\
Al & 0.02 &,, \\
Fe & 0.02 &,, \\
Ca & 0.02 &,, \\
\hline Silicon (by difference) & 99.93 &,,
\end{tabular}

The melting point of silicon of purity 99.93 per cent is therefore given as $1,415^{\circ} \pm 2^{\circ} \mathrm{C}$.

The silicon used by Hoffmann and Schulze was slightly less pure $(\mathbf{9 9} .89$ per cent) and it would therefore be expected that the melting point of that sample, namely, $1,411^{\circ} \pm 2^{\circ} \mathrm{C}$., should be a little lower than that described above.

Metallurgy Department, M. L. V. Gayler. National Physical Laboratory, Teddington, Middlesex.

${ }^{1}$ Phys, Z., 33 (22), 901 (1937).

${ }^{2} J$. Iron a.2d Steel Inst., 115, 412 (1927).

\section{Photochemical Equivalent in Optical Sensitizing}

IN a communication to NATURE' entitled "Mechanism of Optical Sensitizing of Silver Halides by Dyes", we described briefly some experimental results showing that sensitizing dyes adsorbed to silver halides produce by absorption of light in their own absorption bands decomposition of the silver halide into metallic silver and free halogen. In the presence of adequate halogen acceptors, the dye remains chemically unchanged.

The mechanism of the energy transfer in this process has not yet been explained adequately. G. Scheibe ${ }^{2}$, following the suggestions of Gaffron, Weiss and others, has applied the idea of quantum summation to dye sensitizing of photographic plates. According to this, large polymeric aggregates of dye molecules may absorb several quanta simultaneously and, in some unexplained fashion, integrate smaller quanta to form larger ones. In some such manner it is suggested that a quantum large enough to decompose silver halide is obtained from smaller quanta absorbed by the dye.

There are a number of reasons from photographic observations and theory which argue against this, but it is evident that a primary experimental datum is the photochemical equivalent. In continuing under 